\title{
PREMENSTRUAL SYMPTOMS IN WOMEN WHO ATTEMPT SUICIDE
}

\author{
Major R. N. T. THIN, M.B., M.R.C.P., (Edin.), R.A.M.C. \\ Royal Herbert Hospital, Woolwich
}

Frank (1931) reported physical and psychological symptoms developing during the ten days before menstruation and usually stopping at its onset. He thought that about ten per cent of women were troubled by these symptoms, but Coppen and Kessel (1963) considered that most women suffered from them at some time between menarche and menopause. Since Frank's observation numerous reports on this cyclical syndrome have been published: for instance Pennington (1957) studied American women, and Sutherland and Stewart (1965) studied British students.

It was observed that many women admitted to a poisoning treatment centre after attempting suicide started a period on or about the day of admission. This paper consists of a comparison of premenstrual symptoms of 100 of these women (Group 1) with the symptoms of 57 women admitted to hospital with acute organic medical conditions (Group II), and those of 68 apparently healthy women who sought advice about matters unrelated to their own health (Group III). As none of the women in Group I used oral contraceptives, all the women who took these drugs were excluded from Groups II and III. The increasing use of these contraceptives made it impossible to match all the patients in Group I with individuals in the other two groups.

\section{Method}

Normally-menstruating women aged fifteen to forty-four years seen during eight months in a poisoning treatment centre and at various military stations were admitted to the study. The subjects were interviewed and questioned about their menstruation and premenstrual symptoms using a simple questionnaire which did not include questions to assess personality. They were asked to grade symptoms as significant or insignificant. Significant symptoms were those present for at least one whole day before six or more periods during the preceding year. Only significant symptoms are considered and the subjects' own assessments were accepted, for they alone were able to assess their own symptoms.

\section{The subjects}

\section{Results and discussion}

Details of the marital status, age distribution, parity, and menstrual history are shown in Table I. Those in Group I described as married include all who cohabitated; those described as widows include all divorcees and women separated from their husbands but not cohabitating with another man. All the subjects in Groups II and III were married or single in the accepted sense. Although the age distribution varied between the groups, the only significant difference was in the age bracket forty to forty-four years where Group I was larger. Parity was highest in Group III.

\section{Admission in relation to menstruation}

Figure 1 shows the day of admission for each Group I patient relative to her menstrual cycle plotted on a 28 day graph. Sixteen patients started a period on the day 
Table 1

Details of marital status, age distribution, parity and menstrual history of the subjects in the three groups

\begin{tabular}{|c|c|c|c|c|c|c|c|}
\hline & & \multicolumn{2}{|c|}{ Group 1} & \multicolumn{2}{|c|}{ Group 11} & \multicolumn{2}{|c|}{ Group 111} \\
\hline & & Number & Per Cent & Number & Per cent & Number & Per cent \\
\hline \multicolumn{2}{|c|}{ Total number of subjects } & 100 & 100.0 & 57 & 100.0 & 68 & 100.0 \\
\hline \multicolumn{2}{|l|}{$\begin{array}{l}\text { Married } \\
\text { Single } \\
\text { Widowed }\end{array}$} & $\begin{array}{l}45 \\
31 \\
24\end{array}$ & $\begin{array}{l}45.0 \\
31.0 \\
24.0\end{array}$ & $\begin{array}{r}15 \\
42 \\
0\end{array}$ & $\begin{array}{c}26.3 \\
73.7 \\
0\end{array}$ & $\begin{array}{r}56 \\
12 \\
0\end{array}$ & $\begin{array}{c}82.3 \\
17.7 \\
0\end{array}$ \\
\hline $\begin{array}{l}\text { Age distribution } \\
\text { (years) }\end{array}$ & $\begin{array}{l}15-19 \\
20-24 \\
25-29 \\
30-34 \\
35-39 \\
40-44\end{array}$ & $\begin{array}{l}15 \\
18 \\
19 \\
19 \\
17 \\
12\end{array}$ & $\begin{array}{l}15.0 \\
18.0 \\
19.0 \\
19.0 \\
17.0 \\
12.0\end{array}$ & $\begin{array}{r}18 \\
12 \\
9 \\
8 \\
7 \\
3\end{array}$ & $\begin{array}{r}31.6 \\
21.1 \\
15.8 \\
14.2 \\
12.1 \\
5.2\end{array}$ & $\begin{array}{r}8 \\
10 \\
15 \\
23 \\
11 \\
1\end{array}$ & $\begin{array}{r}11.8 \\
14.7 \\
22.2 \\
33.8 \\
16.2 \\
1.5\end{array}$ \\
\hline \multicolumn{2}{|l|}{ Mean age (years) } & \multicolumn{2}{|c|}{28.8} & \multicolumn{2}{|c|}{25.5} & \multicolumn{2}{|c|}{26.2} \\
\hline Parity & $\begin{array}{l}0 \\
1 \\
2 \\
3 \\
3+\end{array}$ & $\begin{array}{r}42 \\
26 \\
13 \\
11 \\
8\end{array}$ & $\begin{array}{r}42.0 \\
26.0 \\
13.0 \\
11.0 \\
8.0\end{array}$ & $\begin{array}{r}44 \\
2 \\
5 \\
3 \\
3\end{array}$ & $\begin{array}{r}77.2 \\
3.4 \\
8.8 \\
5.3 \\
5.3\end{array}$ & $\begin{array}{r}16 \\
11 \\
16 \\
17 \\
8\end{array}$ & $\begin{array}{l}23.6 \\
16.0 \\
23.6 \\
25.0 \\
11.8\end{array}$ \\
\hline \multicolumn{2}{|l|}{ Mean parity } & \multicolumn{2}{|c|}{1.17} & \multicolumn{2}{|c|}{0.57} & \multicolumn{2}{|c|}{2.2} \\
\hline \multicolumn{2}{|l|}{ Regular cycle } & 76 & 76.0 & 43 & 75.5 & 62 & 91.2 \\
\hline \multicolumn{2}{|c|}{$\begin{array}{l}\text { Menarche mean (years) } \\
\text { Standard deviation } \\
\text { Duration of period mean } \\
\text { (days) } \\
\text { Standard deviation }\end{array}$} & \multicolumn{2}{|c|}{$\begin{array}{l}13.2 \\
1.66 \\
4.7\end{array}$} & \multicolumn{2}{|c|}{$\begin{array}{l}12.5 \\
2.16 \\
6.1\end{array}$} & \multicolumn{2}{|c|}{$\begin{array}{l}13.5 \\
1.34 \\
5.1\end{array}$} \\
\hline
\end{tabular}

of admission. This is significantly greater than the expected daily mean based on a 28 day cycle, which is 3.57 ( $p<0.01$ ). The disproportionate number admitted on Day 1 indicates considerable psychological disturbance immediately before the onset of a period. No pattern was found when the day of admission of patients in Group II was plotted in a similar manner.

Dalton (1959) found that 39 per cent of 36 patients who had attempted suicide were admitted to hospital between Days 1 and 4 of their menstrual cycles. This was a higher incidence than in any other four day period of the cycle. The finding here that 16 per cent of attempted suicides were admitted on Day 1, confirms Dalton's findings but shows that psychological disturbance occurs immediately before the onset of menstruation, rather than coinciding with it as he suggests. It also confirms other evidence of acute psychological disturbance in the premenstruum such as a high rate of acute psychiatric illness, criminal activity, misbehaviour, and accidents. (British Medical Journal, 1963).

\section{Premenstrual symptoms}

The highest.incidence of symptoms was in Group I (Table II). Headaches, other pains, vomiting, emotional instability, lethargy, depression, and swelling of the abdomen 


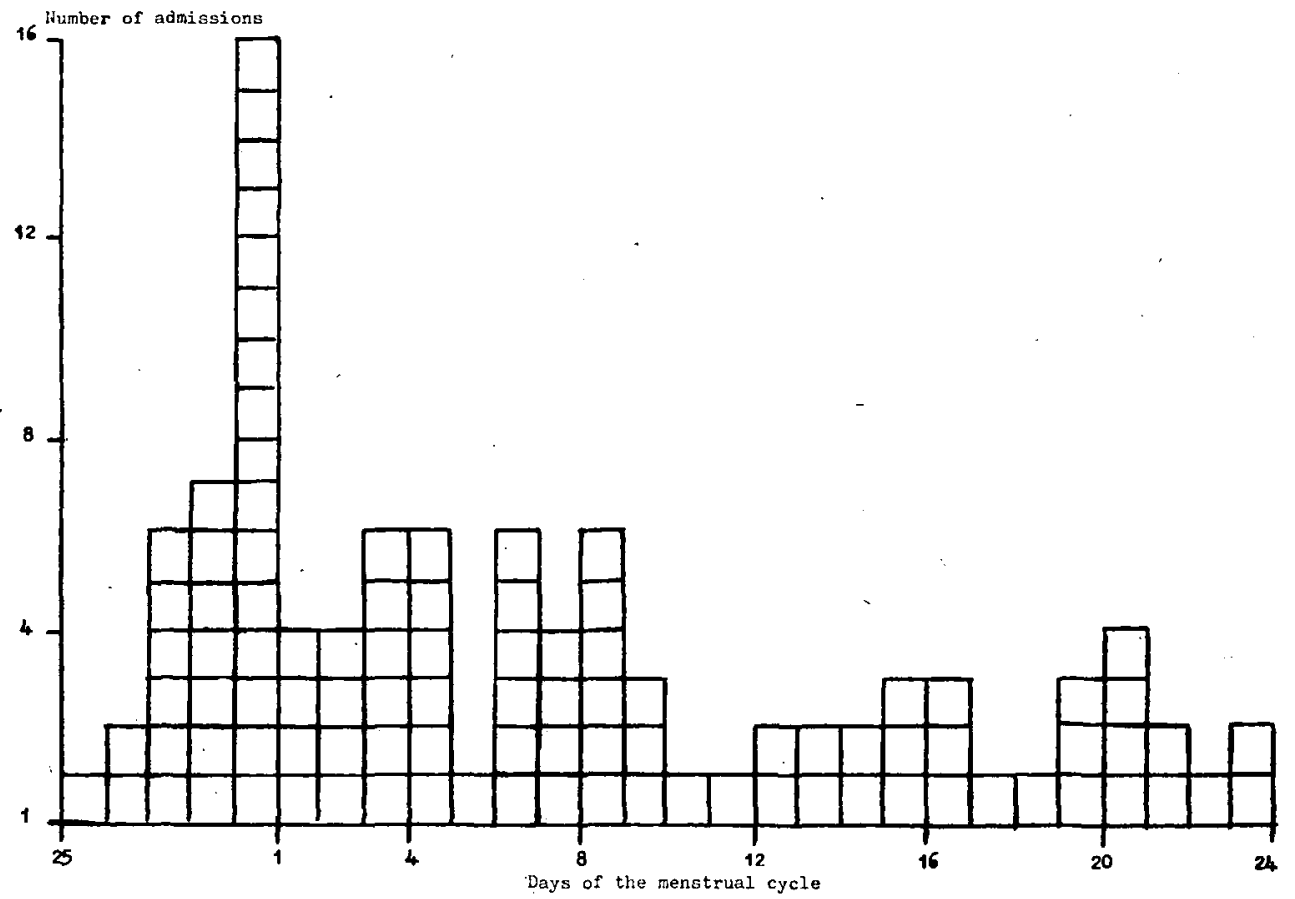

Fig. 1-Day of admission of patients in Group 1 relative to their menstrual cycle

Table II

Incidence of premenstrual symptoms in the three groups

\begin{tabular}{l|r|r|r|r|r|r}
\hline & \multicolumn{2}{|c|}{ Group I } & \multicolumn{2}{|c|}{ Group II } & \multicolumn{2}{c}{ Group III } \\
\cline { 2 - 7 } & Number & Per cent & Number & Per cent & Number & Per cent \\
\cline { 2 - 7 } Total number of subjects & 100 & 100.0 & 57 & 100.0 & 68 & 100.0 \\
\hline Headaches & 46 & 46.0 & 25 & 43.8 & 9 & 13.2 \\
Other pains & 68 & 68.0 & 15 & 26.3 & 12 & 17.7 \\
Nausea and vomiting & 29 & 29.0 & 7 & 12.3 & 3 & 4.4 \\
Emotional instability & 60 & 60.0 & 31 & 54.4 & 27 & 39.7 \\
Lethargy & 58 & 58.0 & 3 & 5.3 & 15 & 2.2 \\
Depression & 74 & 74.0 & 21 & 36.8 & 19 & 28.0 \\
Stomach swelling & 32 & 32.0 & 20 & 35.1 & 11 & 16.4 \\
Breast swelling & 3 & 3.0 & 6 & 10.5 & 3 & 4.4 \\
Ankle swelling & 3 & 3.0 & 4 & 7.0 & 5 & 7.6 \\
Vaginal discharge & 0 & 0 & 6 & 10.5 & 4 & 5.9 \\
Other symptoms & 7 & 7.0 & 20 & 35.1 & 11 & 16.4 \\
No symptoms & 6 & 6.0 & 6 & 10.5 & 10 & 14.7 \\
\hline
\end{tabular}

were the most commom symptoms in all the groups and the raised incidence in Group I was significant for these symptoms $(p<0.01)$. Only 60 per cent of subjects in Group I considered themselves to be emotionally unstable. The high incidence of patients in Group I ( 29 per cent) who suffered from nausea and vomiting is curious and may be related to emotional instability; this was much less common in the other groups. "Other symptoms" included disturbance of micturition, diarrhoea, constipation, syncopal attacks, food fads, and hyperkinetic behaviour. 
These findings show that psychological premenstrual symptoms are more common in women who attempt suicide than in women with acute organic medical disease, or in healthy women. Coppen and Kessel (1963) took irritability as their key symptom and found that it was significantly increased by marriage, but was unaffected by subsequent childbirth. The proportion of married women was highest in the healthy subjects, so their expected incidence of psychological symptoms is high; in fact it was the lowest. It is concluded that the difference in the incidence of psychological symptoms between the groups is real.

Coppen and Kessel (1963) found that psychological premenstrual symptoms were significantly correlated with neuroticism. Details of the final psychiatric diagnosis were not known in many of the attempted suicides (Group I), because they had further psychiatric care after leaving the poisoning treatment centre. However, preliminary assessment showed a high incidence of neuroticism and other abnormal personality traits; furthermore, the proportion of women with significant premenstrual symptoms was highest in the attempted suicides and lowest in the healthy women. This appears to confirm Coppen and Kessel's conclusion that premenstrual symptoms are an exacerbation of personality traits which in turn are related to neuroticism.

The absence of any assessment of personality in the questionnaire may be partly responsible for the high incidence of symptoms among the women who attempted suicide; neurotics gave a high proportion of positive answers. However, this raised incidence of symptoms among these women can be regarded as another measure of their neuroticism.

\section{Summary}

The incidence of significant premenstrual symptoms has been assessed in women who attempted suicide, and had been compared with the incidence in women with acute organic medical conditions, and in healthy women. It was highest in the first group, intermediate in the second, and lowest in the third. A high proportion of the women who attempted suicide started a period on the day of their admission to hospital.

\section{REFERENCES}

British Medical Journal. (1963). i, 1000

COPPEN A. and KeSSEL N. (1963). Brit. J. Psychiat., 109, 711.

Dalton, K. (1959). Brit. med. J., i, 148.

Frank R. T. (1931). Arch. Neurol. Psychiat., 26, 1053.

Pennington, V. M. (1957). J. Amer. med. Ass., 164, 638.

SutherLand H. and STEWARD I, (1965). Lancet, i, 1180. 